\title{
How to integrate the aging of employees into occupational health policies: The approach of a French company
}

\author{
Monique Bonnet-Belfais ${ }^{\mathrm{a}, *}$, Jean-François Cholat ${ }^{\mathrm{a}}$, Denis Bouchard ${ }^{\mathrm{b}}$, Charles Goulfier ${ }^{\mathrm{a}}$, \\ Adina Casselle ${ }^{\mathrm{c}}$ and Jean Schram ${ }^{\mathrm{a}}$ \\ ${ }^{a}$ Health Corporate Delegation, EDF SA, Levallois-Perret, France \\ ${ }^{\mathrm{b}}$ Employment Unit for Ile-de-France Area, EDF SA, Levallois-Perret, France \\ ${ }^{\mathrm{c}}$ Research and Development Unit, EDF SA, Levallois-Perret, France
}

Received 4 July 2012

Accepted 15 March 2013

\begin{abstract}
.
BACKGROUND: Since 2010, French companies must integrate or retain seniors to avoid a fine of $1 \%$ of their payroll. OBJECTIVE: This work examines how to integrate the aging of employees into occupational health policies.

METHODS: The literature on the complex relationships between age, work and health has been reviewed, and the feasibility of potential actions has been addressed.

RESULTS: In the company setting, few diseases are specific to seniors. With retirement age postponing, chronic diseases may appear more frequently in people still working. Physiological aging linked to a functional decline is variable. Occupational wear and tear can result in some functional deterioration. Seniors can experience difficulties coping with heavy time demands that restrict their ability to organize the work, with physical stresses due to their diminished muscular capacity, and with unconventional schedules that have long-term deleterious effects on sleep quality and alertness.

CONCLUSIONS: This position paper makes recommendations for adapting work organization and occupational medical care. Protective measures for seniors should be integrated in a global approach to improving work conditions for all. Aging employees need some leeway to develop experience-based strategies for bypassing new difficulties. Revising work rhythms and developing autonomy seem to be means for progress.
\end{abstract}

Keywords: Organization of work, human resource management, autonomy, occupational physical and mental wear and tear, shift work

\section{Introduction}

The aging of the population in developed countries is now well known. According to the 2010 Revision of the United Nations demographic projections [1], the proportion of population over 60 should increase from

* Corresponding author: Monique Bonnet-Belfais, EDF SA. Service Etudes Médicales, 45 rue Kléber, 92309, LEVALLOISPERRET, France. Tel.: +33 1822484 30; E-mail: monique.bonnetbelfais@edf.fr.
$22 \%$ in 2010 to $32 \%$ in 2050 and $33 \%$ in 2100 . The United States and then later European countries have already taken measures to address the problem in terms of public financial imbalance. In Europe, the effects of the overall aging of the population have led different countries to push back the legal retirement age. Companies must henceforth recruit or keep older employees, thereby modifying their staff demographic structure. However, as in the United States [2], up to now, very few European companies have addressed the impact of an aging workforce on occupational health and 
Source: EDF SA. DEC. (Employment and Skills Unit). 2008

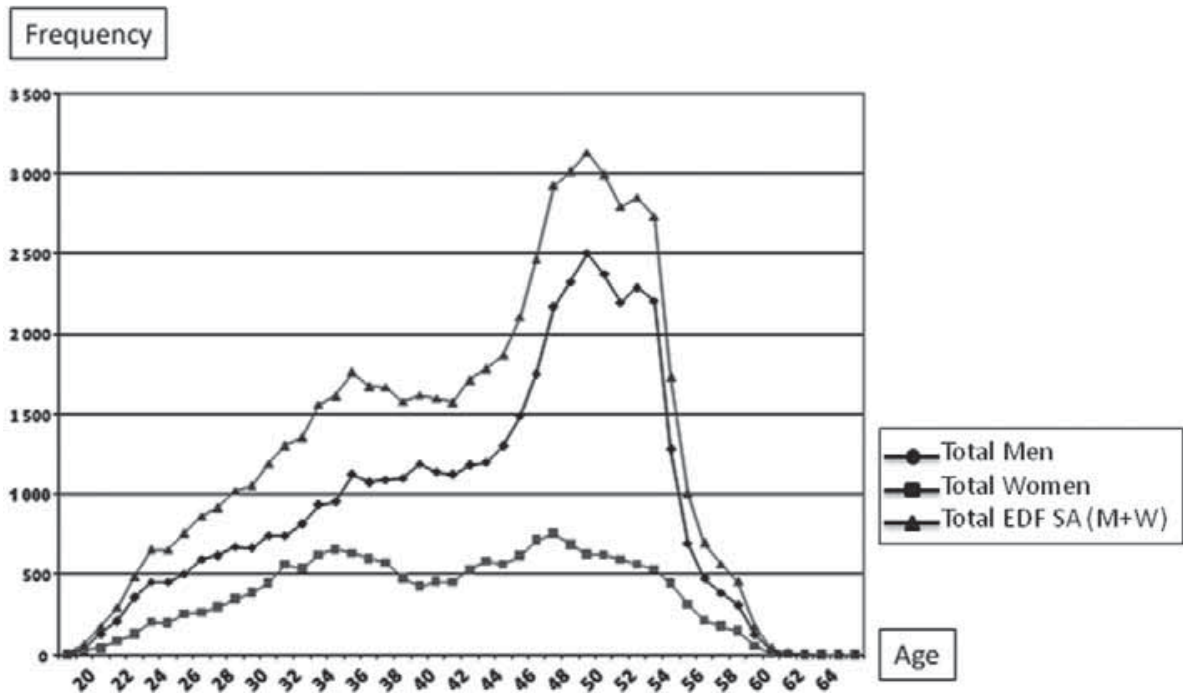

Fig. 1. EDF SA Age distribution.

work conditions. In order to integrate aging in its Occupational Health Policy, the French electricity company EDF SA, has carried out a study about the potential health impact of aging among employees. The main purpose of this study was to help clarify how Human Resources and Occupational Health Services should adapt work organization and occupational medical care, and so, keep all their employees in good health throughout their prolonged occupational life and further.

\section{Demographic, political and regulatory background}

Integrating aging into an occupational health policy needs to take into account several closely related aspects - demographic characteristics, political and regulatory measures, experiments tried in European countries - before disentangling multiple links between age, work and health.

\subsection{Aging in Europe}

According to demographic projections in the European Union (EU-27) up to the year 2060, the European population will slightly increase, and above all, will age $[3,4]$. By 2060 , people over the age of 65 , constituting $17 \%$ of the population in 2008 , are projected to represent $30 \%$ and proportions over the age of 80 should triple to reach $12 \%$. For every person over the age of 65 , there should be only two people of working age -from 15 to 64 years old- instead of four people currently.

However, there are significant projected differences from one country to another. For example, in Poland the median age should rise by 15 years, whereas it should rise by less than 5 years in Great Britain or in France. Also, the population of people of working age in France is projected to increase by $2 \%$ between 2008 and 2060 , while it is expected to decrease by $15 \%$ overall in the EU-27.

The new, intergenerational ratio observed in the overall population, should also be seen to a greater or lesser extent in the age structure of companies.

In EDF SA, there were 60,360 people in the statutory employee cohort in 2008 , whose average age was 43.6, with a rather marked difference among bluecollar workers (these were younger - 38.7 years of age on average). The age distribution of employees (Fig. 1) is bimodal; the first peak is at age 36 ( 35 for women), and the second at 50 (48 for women). For men, the second peak of frequency at 50 years is clearly more important, whereas for women, both peaks have more or less the same level.

In $2008,51 \%$ of EDF workers were aged 45 or over and $31 \%$ were 50 or over. In comparison, in 2004, employees aged 50 and over represented $22 \%$ of the company's staff. These figures confirm that EDF SA's age structure is also changing. Employees aged 55 and over, which currently only represent $5 \%$ of the staff, should logically increase in number as a result of the extension of working life. 


\subsection{European strategies}

In most European countries, public pension schemes remain the core of the retirement pension systems, functioning on the principle of the solidarity between generations in which retired people pensions are paid by contributions of people currently working. To keep public funds viable, several European States have implemented a strategy intended both to adapt their social protection and pension plans, and to increase the employment rates, especially for women and older workers. In 2008, a public hearing organized by the European Parliament drew the conclusion that the retirement pension system, based on solidarity between generations, could be maintained, provided that the employment rate for seniors (55-64 years old) reaches Sweden's rate $(72.9 \%)$ in the majority of European countries and that the employment rate for women rises to the level of the employment rate for men [5].

There have been experiments to increase senior employment. For example, in late 1995, Finland launched the "active aging" model, which implemented largescale, social mobilisation programmes, applied at all levels by various organizations, including the Finnish Institute of Occupational Health. This model, characterized by a strong cooperation from labour and management as well as local, regional and national networks, encouraged the acceptance of prolonging working life and supported older workers by improving their working conditions. With a spectacular increase in Finland's senior (55-64 years old) employment rate by more than $19 \%$ over 12 years (from $35.5 \%$ in 1994 to $54.5 \%$ in 2006), the Finnish strategy can be considered as a success, even if it was better at retaining jobs for older employees than it was at reintegrating older unemployed people. However, in their evaluation, experts consider that it is related to a uniquely Finnish context and so difficult to transfer to other countries [6].

Keeping in line with the EU strategy, France restructured the pension scheme and promoted employment for people aged 50 and over. The pension scheme reform took place in several phases from 1993. The minimum retirement age was pushed back to 62 and the full state pension age to 67 . To increase the employment rate for the 55-64 age group, which was lower in France than in the European Union (38\% vs. $46 \%$ in 2008), the French authorities took measures to promote senior employment. Since $1^{\text {st }}$ January 2010, a law requires companies with more than 50 employees to recruit employees over the age of 50 or to maintain employees over the age of 55, under penalty of $1 \%$ of their payroll.
Finally, the measures deployed by European countries, as well as the few experiments carried out by certain companies, have focussed mainly on guaranteeing the financial balance of their social protection and pension plans and increasing the senior employment rate, without addressing the potential health impact of aging among employee population. Yet, companies have to face it for implementing solutions in the long run. It requires a thorough understanding of the complex relationship between age, work and health. Especially, it is necessary to be clear how the age factor intervenes into the different aspects - negative and positive - of the link between work and health.

\section{Methods}

The adopted methodological approach to examining links between age, work and health consisted of a literature review using international and French databases and a review of specific research centers or agencies works. It was completed by the work of a one-year experts group.

The literature review was conducted in 2009 using the international database Pubmed, and also the French Public Health database BDSP. As a matter of fact, for a long time, France has been developing particularities within the occupational health medicine field, and big companies, like EDF SA, have their own occupational health services. Dedicated research centers have carried out several projects on workforce health, whose full results have only been published in French [7-22].

Numerous keywords have been used for the search strategy: Health, occupational health, age, aging, seniors, work, workplace, work conditions, work organization, shift work, unconventional schedules, sleep disorders or disturbance, retirement, work ability, work strenuousness, physical and psychological attrition, occupational physical and mental wear and tear, musculoskeletal disorders, Repetitive Strain Injuries.

The keywords used for retrieving articles in the French database were the equivalent terms in French.

Each of the three items "work", "age" and "health" gave rise to a lot of works. Also, works exist regarding association of one variable with another. However, in spite of an apparent abundance of resources on each item or items in pairs, rather few articles dealt with the multiple links between the three subjects.

In addition, another approach has been implemented too, by systematically considering works carried out by specific research centers or on specific cohorts or 
surveys, regarding their link, even partial, to the three items of work, age and health. It was especially the case of the following French institutions or organizations: the Centre for Research on Age and Working Populations (CREAPT), the Centre for Employment Research (CEE), the Institute for Research and Information in Health Economics (IRDES), the National Institute of Safety Research (INRS), the National Agency for the Improvement of Working Conditions (ANACT), the National Institute for Health and Medical Research (INSERM), the National Institute of Statistics and Economic Studies (INSEE). Results of several surveys or cohorts have been reviewed too, especially from the SHARE Survey (Health, Aging and Retirement in Europe), the EWCS Survey (European Working Conditions), the French survey SVP 50' (Health and Professional Life after the Age of 50), the ESTEV Survey (Health, Work and Aging) and the GAZEL Cohort (gas and electricity utility company workers).

Moreover, the feasibility of potential actions to implement inside companies like EDF SA has been addressed by an in-house working group made up of experts in occupational health, ergonomics, epidemiology, occupational diseases, protection plans, human resources management, and research development. The main objective of this group was to identify the levers for action by retaining the most relevant proposals among those described in the literature. This paper draws on European data and studies, but for the levers for action, it mainly focuses on France to fit better to the EDF SA context.

So, this article can be considered as a position paper based on a thorough review of the literature in order to develop an occupational health policy integrating aging.

\section{Results: Age, work and health in a complex relationship}

The literature review highlighted how difficult it is to understand the effective role of age within the relation between work and health [23]. Results have been sorted in four parts and are summed up in the four next subsections. First, the review confirmed that the issue of aging populations cannot be managed by postponing mechanically the retirement age only. Second, it showed that studies were faced with difficulties of an objective measurement of work conditions and state of health. Third, it illustrated that links between age, work and health are multiple, complex, difficult to synthesize, but very informative. Finally, it permitted to identify potential pathologies affecting seniors at work.

\subsection{Work strenuousness and healthy life expectancy: Two moderating factors in prolonging working life}

The overhaul of the French pension scheme was accompanied by the examination of the issue of work strenuousness. This led initially to seeking a potential, objective compensation system to be integrated into the pension plans, but it helped describe the concept of work strenuousness, which was largely addressed afterwards in health studies $[8,11,12,15]$. Schematically, two types of work strenuousness can be distinguished. The first one is largely consensual, measured objectively, and could be compensated for in pension plans. The second one is more subtle, related to the physical or psychological wear and tear rising from situations difficult to bear over the long-term. This second form of work strenuousness is rather significant in aging employees.

A second notion also comes into play - that of Healthy Life Expectancy, that is life expectancy without disability and without restriction on every day activity.

In France, healthy life expectancy at birth has increased more or less in the same manner as life expectancy at birth (Table 1). Nevertheless, healthy life expectancy at birth represents approximately 20 years less than life expectancy at birth in women and 15 years less in men.

In addition, in 2007, healthy life expectancy at 65 in France was 9.9 years for women and 9.4 years for men.

There are some disparities among European countries for healthy life expectancy (Table 2). In 2007, Germany brought up the rear with 58.8 years for men and 58.4 years for women, while Sweden was the leader with 67.5 years for men and 66.6 years for women. Furthermore, the well-known difference in life expectancy between men and women diminishes if we consider healthy life expectancy. In Germany, Spain, Italy and Sweden, healthy life expectancy is even slightly longer for men than for women.

Regarding retirement age postponing issues, Healthy Life expectancy indicator gives an advantage over Life Expectancy indicator because it takes into account Repetitive Strain Injuries (RSIs or musculoskeletal disorders) that are increasing with age.

So, Work strenuousness and healthy life expectancy should be a moderating influence on the consideration of a more extended professional active life. 
Table 1

Life Expectancy and Healthy Life Expectancy. Sources: INSEE (the French National Institute of Statistics and Economic Studies). EUROSTAT. 2009 In years

\begin{tabular}{llcccc}
\hline & & 1995 & 2000 & 2005 & 2007 \\
\hline \multirow{2}{*}{ Women } & Life expectancy at birth & 81.9 & 82.8 & 83.8 & 84.5 \\
\multirow{3}{*}{ Men } & Healthy life expectancy at birth & 62.4 & 63.2 & 64.3 & 76.2 \\
& Life expectancy at birth & 73.9 & 75.3 & 76.8 & 62 \\
& Healthy life expectancy at birth & 60 & 60.1 & 63.1 & 62 \\
\hline
\end{tabular}

Table 2

Healthy Life Expectancy at birth through European Countries in 2007 (Sources: EUROSTAT. 2009)

\begin{tabular}{lcccccc}
\hline & Germany & Spain & France & Italy & United Kingdom \\
\hline Women & 58.4 & 62.9 & 64.2 & 62.0 & 66.2 & Sweden \\
Men & 58.8 & 63.2 & 63.1 & 62.8 & 66.6 & 64.8 \\
\hline
\end{tabular}

\subsection{Measurement difficulties of work conditions and state of health}

All the surveys and studies have come up against difficulties in obtaining accurate measurements. These difficulties are a result of, on the one hand, the multidimensional nature of concepts difficult to grasp objectively (work strenuousness, work organization, health) and, on the other hand, the unavoidable biases, especially with self-declared data.

To integrate this multidimensional nature of the concepts of health, work strenuousness and their relationships, Finland devised the Work Ability Index (WAI) in the '90s [24-27]. This indicator of work capacity retention is a measurement that takes into consideration work requirements, the employee's state of health and the employee's resources. For all of the studies using WAI worldwide, the common result is a decline in work ability with age.

Some biases in the studies can be attributed to cultural or linguistic differences. For example, European SHARE survey [9] showed that the Danes often mention "very good or excellent health" for what the Belgians or Dutch would consider just "good health". Furthermore, all else being equal, older people would tend to state that they are in better health than younger [9].

Nonetheless, research organizations concur in considering a strong correlation between the objective and subjective measurements in the field of work conditions [18] and also in the field of health [28]. So, perceived state of health is a good assessment of real state of health. The same is true for work conditions.

\subsection{Main results of the surveys or studies on multiple links between age, work and health}

Several surveys were carried out in Europe about age, work and health: ESTEV survey and SVP 50 sur- vey in France, SHARE survey in Europe. The most relevant results are detailed below, in a chronological order. In addition, several results from specific studies on work with unconventional schedules are presented. Finally, cohort studies results from the British Whitehall II cohort and the French GAZEL cohort are reported.

Some 20 years ago, the French 1990 ESTEV Survey $[10,29]$ studied the role of occupational factors on aging among 21,000 salaried men and women and intended to address the consequences of aging, especially in terms of fitness for work. Two types of aging in the workplace were distinguished, the "premature aging" as a result in part of demands or disturbances imposed by a job, and aging at work, when the advancing age of an employee affects his (or her) capacity to fulfil the job requirements. Three main results were obtained. First, unconventional schedules or shift work reinforce strongly sleep disturbances and these increase with age. Moreover, this negative effect persists among former workers with unconventional schedules, especially after the age of 47 . Second, the prevalence of back pain increases with age and is not only related to carrying heavy loads but also to work organization as a lack of leeway or means to perform high quality of work. Third, among women, psychotropic drugs use increases with the need to work quickly, especially after the age of 47. Overall, even though physical health changes increase with age (RSI, sleep disturbances, blood pressure, hearing), not everyone has the same problems at the same age. So, age appears to be a factor that has a separate role, which accumulates with other factors.

These results have been confirmed through the French survey SVP50 on health in the workplace for 11,200 employees after the age of 50 [7], especially the long-term negative effects of shift work on sleep disturbance and anxiety. With age, functional capacities diminish in terms of muscular strength, range of joint 
motion, vision, hearing, sleep regulation, short-term memory, and the ability to make many decisions in a limited time frame. Also, pain, fatigue, motor troubles, and the need for more time increase with age, with a maximum observed at 56-57 years of age. Moreover, the risk of chronic illness increases with age especially after the age of 65 . However, health troubles do not always interfere with work, depending on the nature of the disorders and their seriousness, as well as on the flexibility that the employees have for adjusting their movements or rhythms (schedules, cadence of tasks flows, and sequence of tasks ....).

Several studies have been carried out from the $E u^{-}$ ropean SHARE Survey (Survey on Health, Aging and Retirement in Europe) [9,19] conducted in 11 European countries (Germany, Austria, Belgium, Denmark, Spain, France, Greece, Italy, the Netherlands, Sweden and Switzerland) among 45,000 individuals in 2004 and in 2006.

One study examined the correlation between work strenuousness and the health of workers aged 50 or over [19]. At first, the protective effect of work is highlighted: working people aged 50 to 65 have better health than people who do not work. Then, it is the "rewards received" dimension that is most strongly related to the state of health of seniors: "receiving a substantial reward is correlated with a higher probability of judging oneself to be in good health" and of not suffering from depression. Moreover, among seniors, poor health is related to the imbalance described by Karasek and Theorell in 1991 [30], which is the association of high psychological demand with low decisionmaking flexibility, and to the imbalance described by Siegrist in 1996 [31], i.e., when the reward received is not on par with the effort made: men experiencing these imbalances feel less healthy and women suffer more from depression. Furthermore, a lack of support at the workplace increases the risk of depression, especially in women, whereas perceived job security increases the probability of feeling healthy and diminishes the risk of depression.

A second study based on SHARE data compared the work capacity of aging workers in different European countries in terms of working conditions satisfaction and perceived state of health [9]. It is pointed out that seniors in Nordic and Continental countries are more satisfied with their working conditions and their state of health than Mediterranean seniors. Yet, in Mediter- ranean countries, the "healthy worker effect" $\left(\mathrm{HWE}^{1}\right)$ is stronger, in particular because employers tend to employ younger people (supposedly in better health) than in Northern European countries. One explanation proposed is that in Northern European countries, the implemented "active aging" strategy retain in employment people who are not as healthy as they feel, but who are satisfied to be maintained at work.

Moreover, this study reports that in France, there would be a general intensification of work experienced by aging workers too.

In addition to surveys results, some relevant findings come from specific research teams.

Several studies $[13,14,17,32-34]$ have indicated that the organization of work could have consequences on the quality and the quantity of sleep, and eventually on health: metabolic disorders, cardiovascular disorders, increased risk of accidents, and even, according to some, breast cancer in women.

In France, $40 \%$ of chronic insomniacs claim an occupational cause. $20 \%$ of French employees work unconventional schedules, perform shift work or work nights. This type of work is associated with desynchronising the human biological clock which signals sleep and regulates internal temperature, hormone secretion, heart rate and blood pressure, respiratory rate, renal function, and so on. According to Léger et al. [13,14], the potential short- and long-term health effects of shift work and working nights are various: sleep deficits generating drowsiness and a loss of alertness, digestive problems, possibly due to excessive consumption of coffee, ischemic heart disease with a risk increased by 20 to $40 \%$, hypertension and diabetes. Moreover, there is a higher risk of two different types of cancer: breast cancer in women performing shift work, colorectal cancer in people who have been working nights for several years. Since 2007, shift work that involves circadian disruption is classified by the World Health Organization as a probable human carcinogen, group 2A [34]. Very recently, the International Agency for Research on Cancer defined several aspects of shift work that should be captured in future epidemiological cancer studies [35].

Also, with age, the biological clock becomes less flexible. So, for an older person adapting to irregular schedules or night work becomes more difficult, and

${ }^{1}$ HWE: Usually overall mortality or morbidity rates among workers are lower than in the general population because people who are severely ill and chronically disabled are ordinarily excluded from employment. 
age has been found to increase the risk of cardiovascular conditions in shift workers [14].

In the end, relevant findings arise out of cohort studies.

The GAZEL Cohort was set up in 1989 by the French National Institute for Health and Medical Research. Initially, it included 20,625 volunteers aged 35 to 50 working at public gas and electricity utility company (EDF GDF). They were followed throughout their life [36]. Very recent studies conducted on the 14,700 retired EDF GDF employees from this cohort demonstrated the strong, positive effect that retiring had on perceived state of health and sleep disturbances, especially in those who had experienced poor working conditions $[37,38]$.

Concerning cognitive problems, another interesting result has been found in a study from the British Whitehall II cohort launched in 1985, involving 10,308 British civil servants aged 40 to 69 [39]. It suggested that a relationship exists between a lack of "good" cholesterol (HDL-) and short-term verbal memory deficits in adults more than 60 years old. At that age, people could be more likely still working. This information could foster HDL-C cholesterol surveillance among measures to put in place in the framework of an occupational prevention campaign.

\section{Pathologies in seniors}

The various research efforts that have been conducted for over 20 years have made it possible to highlight significant issues regarding the pathologies affecting seniors.

Firstly, it is crucial to understand that few diseases are specific to seniors. The majority of pathologies can arise at any age; only degenerative diseases related to aging, like Alzheimer's disease, are specific to the elderly. The average age of people with age-related degenerative illness is 82 , making the development of such diseases unlikely in the working environment.

However, the frequency of many diseases increases with age. This is the case for long-term, chronic diseases such as cancer, diabetes, chronic bronchitis, heart disease, and osteoarthritis or rheumatoid arthritis. Up to now, these pathologies appeared when people were already retired. With the postponing of retirement age, chronic diseases could be appeared more frequently inside companies among seniors (55-64) still working.

Moreover, natural aging is accompanied by a decline in many functional capacities, which will vary from person to person. This functional decline can affect the senses, perception and balance, as well as the locomotion, cardiopulmonary, and nervous systems, and particularly short-term memory $[7,16]$.

Finally, occupational wear and tear, related to repetitive movements or positions, to the new constraints imposed by tools or organization, to the lack of time or prospects, can worsen physical or psychological attrition and promote the appearance of functional decline [7,8,10,15,29].

The two latter characteristics of aging - functional decline and attrition - can lead to an increase in occupational accidents, musculoskeletal problems, anxiety and nervous breakdown, and even a string of such disorders [8,18,29].

To illustrate the situation in EDF SA in terms of pathologies among seniors, some figures are presented here.

Among EDF SA employees, there were still very few employees over the age of 55 - only 5\% - in 2008. Regarding absences for overall medical reasons, as it was observed in USA [2], the EDF SA seniors are absent slightly less frequently than other age ranges, but they are absent for longer periods. In 2006, osteoarthritis pathologies caused more than $21 \%$ of the absences in employees over 50, and for an average duration of 22 days (vs. $16 \%$ and 18 days in global EDF staff). Psychiatric problems, which caused $8.4 \%$ of the absences in employees over 50, lasted almost 40 days on average (vs. $7.4 \%$ and 33 days in global EDF staff).

\section{Levers for action}

The complexity of the relationship between work, age and health is characterized by many contradictory elements that are now well-known.

The concept of work is ambivalent, sometimes viewed as a burden associated with fatigue and a loss in autonomy, and sometimes viewed as a factor promoting self-fulfilment and the expression of creative freedom [40,41]. Likewise, work is well-known for having both positive and negative effects on health. As for the positive effects, for example, the feeling of social utility achieved through work is important for individual psychological balance [42]. So, "work appears as a central element to creating health, within the scope of the pursuit of physical, psychological and social wellbeing" [20]. However, beyond the role of protecting against health degradation, work can also cause accelerated aging due to unfavourable work conditions or 
work organization. Hence, the state of health of workers at the end of their working life depends on their working conditions and, more generally, the degree of physical and mental stress encountered in their past work [7,10,37,38]. Moreover, in reverse, there is also a relationship between health and work, work retention being dependent on the state of health of the individual. So, age has been identified as one of the situational handicaps leading to employment selection-exclusion: "aging appears to be a massive weakening factor for job retention in that it is in direct contradiction with the constraints and rigidities in a job most often created for those who are most adaptable" [43].

Furthermore, aging is a continuous process that does not begin at the age of 50, and, as well as a genetic component, is closely related to the way in which one has lived and worked beforehand. Health problems that arise earlier in working life, which may at first appear to be trivial, accumulate over time and can develop into chronic or debilitating illnesses that are potentially worsened by professional stresses and disturbances. This means that maintaining the work capacity of today's seniors cannot take place by transferring stresses, especially physical ones, to younger workers.

Companies have a double challenge: they need to keep older employees in good health, and make sure that younger employees will age without any deleterious work effect later on. This is why it is necessary to integrate aging as part of a global approach to improving work conditions for all, conducting case-bycase analyses, while incorporating the diversity of situations without creating conflict between generations. This should be possible, providing it is recognised that the generation gap regarding work seems to be rather more mythical than true. "Building cooperative intergenerational dynamics" is not only possible, but actually frequent [21,22].

Three kinds of stress penalise older employees the most [16]. At first, heavy time demands eliminate the leeway that older workers need to implement measures for anticipating the work to be done. As a matter of fact, people getting older are less adaptable to their environment. This is more or less pronounced, variable from one person to another, but in general, their ability to deal with heavy workload or to jump from one activity to another in a short time reduced. Secondly, physical strains place significant constraints on older employees due to the natural weakening of the locomotor system and muscular capacity. Finally, unconventional schedules, especially shift work, have repercussions on the quality of sleep and level of alertness.
However, by giving aging employees some leeway, they will be able to develop experience-based strategies for bypassing new difficulties. According to Dessors [43], "the employee's skills will offset the 'handicap' of aging" provided that the employee remains in phase with the technical and organizational development of the company. For Kreutz [16], the organization of work must help devise individual rules for minimising the negative effects of the constraint: task mastery, freedom in decision-making, anticipation, control maintenance. These individual adaptive measures are based on experience, knowledge and expertise acquired over time. So, experience can effectively lead to avoiding painful gestures and movements, provided that the employee has the necessary time to implement these individual, experience-based rules.

In summary, for preventing the potential health effects of aging on the working population, recommendations based on the literature review and potentially suitable for EDF SA context could be:

- Improving working conditions for everyone, especially by integrating into job design the fact that the working population is likely to grow older

- Mapping out careers to help alternate between the most strenuous positions and other positions

- Organising work so that all employees have the leeway they need to deploy adaptive strategies based on their own experience

- Adapting the sharing out of tasks to take account of the possible increase of medical absenteeism due to chronic illness

- Organising professional training at any age

- Promoting more cooperative intergenerational relationships, having particular regard to the transmission of experience to younger employees

- Ensuring that occupational health services perform medical monitoring with aging in mind to quickly identify sub-pathological signs, sleep disturbances, joint pain, fatigue, lack of concentration, functional problems and psychosocial problems, which may signify pathologies in the long run, in order to implement the necessary preventative measures.

\section{Conclusion}

Extending working life and the resultant aging of the working population pose a new challenge to companies, which must now rethink their long-term work- 
ing conditions in order to preserve the health of their employees and maintain their employability throughout their professional life. Even if there are still only $5 \%$ of employees over the age of 55 in a company such as EDF SA, a shift in the age structure is occurring. In 2009, Health Corporate Delegation of the French electricity company EDF SA undertook to understand how to take account of the aging issue in its Occupational Health Policy.

Aging, which is nothing but a continuous, natural process, has two facets. One is negative, corresponding to a progressive weakening of some functional capacities, but which can be offset by the other, positive facet, that is the acquisition of new skills through experience, this providing that work constraints do not worsen or accelerate the first facet. If work conditions and organization are favourable, thanks to their experience, aging employees may develop strategies for circumventing these new difficulties.

So, in the framework of a global approach to improving work conditions for all, two factors appear crucial to prolonging working life. First, the reviewing of workplace rhythms is necessary to fight against work intensification, which seems particularly strong in France. This will subsequently help re-establish balance between personal and professional life. Moreover, the unconventional schedules, like shift work, which can be harmful to health, especially after 15 years of practice have to be limited in number of people and in duration throughout the career. Second, work organization must allow for autonomy in order to individuals to develop strategies for adapting to remaining work requirements.

For the French electricity company EDF SA, this study has been the first step towards integrating the aging of its employee population in its occupational health policy in order to contribute to maintain each worker in good health.

\section{Acknowledgements}

The authors would like to acknowledge Pr David ORMANDY from Warwick University, England, for his proofread and his accurate and so helpful remarks, Dr Jacques LAMBROZO the Director of EDF SA Medical Studies Department for his close reading, Stephanie BILLOT and Elisabeth PIGEON in the same department for their helpful support, and Richard BURTON from the British subsidiary EDF Energy for his final review.

\section{References}

[1] United Nations, Department of Economic and Social Affairs, Population Division. World Population Prospects: The 2010 Revision, Highlights and Advance Tables (Working Paper No. ESA/P/WP.220). New York: United Nations, 2011.

[2] Silverstein M. Meeting the challenges of an aging workforce. Am J Ind Med. 2008; 51: 269-80.

[3] Giannakouris K. Ageing characterises the demographic perspectives of the European societies. Luxembourg: Publications Office of the European Union, 2008.

[4] DG Economic and Financial Affairs, Economic Policy Committee, European Commission. The 2009 Ageing Report: underlying assumptions and projection methodologies for EU27 Member States (2007-2060). Brussels: European Commission, 2008.

[5] Le Bras H, Heran F. The demographic future of Europe. Public Hearing at the European Parliament on 28/05/2008. Bruxelles: European Parliament, Policy Department, Economic and Scientific Policy, 2008.

[6] Sterdyniak H. Active Ageing Strategies to Strengthen Social Inclusion, Finland: European Commission.DG Employment, Social Affairs and Equal Opportunities, 2007.

[7] Molinié AF. La santé au travail des salariés de plus de 50 ans. Données sociales: la société française - Edition 2006. Paris: INSEE; 2006. p. 543-53.

[8] Molinié AF, Volkoff S. Départ en retraite: les deux facettes de la <pénibilité> du travail. Paris: Centre Etudes Emploi (CEE), 2003.

[9] Pollak C. Santé et Pénibilité en fin de vie active: une comparaison européenne. Paris: Centre d'études de l'emploi (CEE), 2009.

[10] Touranchet A, Deriennic F, Volkoff S. Santé Travail et âge. Résultats de l'enquête ESTEV 1990. Actualité et dossier en santé publique. 1996; 15: 18-23.

[11] Struillou Y. Pénibilité et retraite: rapport remis au Conseil d'orientation des retraites. Paris: Conseil d'orientation des retraites, 2003.

[12] Poisson J. Rapport d'Information n 910 à l'Assemblée Nationale sur la pénibilité au travail. 27 mai 2008. Paris: Assemblée nationale, 2008.

[13] Léger D. Travail et sommeil. Arch Mal Prof Environ. 2009; 70(3): 243-4

[14] Léger D, Bayon V, Metlaine A, Prevot E, Didier-Marsac C, Choudat D. Horloge biologique, sommeil et conséquences médicales du travail post? Arch Mal Prof Environ. 2009; 70(3): 246-52.

[15] Lasfargues G, Molinie AF, Volkoff S. Départ en retraite et $<$ travaux pénibles>: l'usage des connaissances scientifiques sur le travail et ses risques à long terme pour la sant? Rapport de recherche. Paris: Centre Etudes et Emploi (CEE), 2005.

[16] Kreutz G, Vallet P, Dornier G. Vieillissement Santé Travail. Le point des connaissances. Paris: INRS, 2004.

[17] Gronfier C. Le rôle et les effets physiologiques de la lumière: sommeil et horloge biologique dans le travail de nuit et post? Arch Mal Prof Environ. 2009; 70(3): 253-61.

[18] Gollac M, Volkoff S. Les conditions de travail. Paris: La Découverte; 2007.

[19] Debrand T, Lengagne P. Pénibilité au travail et santé des seniors en Europe, IRDES n ${ }^{\circ} 120$. mars 2007. Paris: Institut de Recherche et Documentation en Économie de la Santé (Irdes), 2007.

[20] Dejours C, editor. Travail, usure mentale: essai de psychopathologie du travail. Paris: Bayard, 2008. 
[21] Delay B. Les jeunes: un rapport au travail singulier? Une tentative pour déconstruire le mythe de l'opposition entre les âges. Paris: Centre d'études de l'emploi (CEE), 2008.

[22] Delay B. Les rapports entre jeunes et anciens dans les grandes entreprises. La responsabilité organisationnelle dans la construction de dynamiques intergénérationnelles coopératives. Paris: Centre d'études de l'emploi (CEE), 2008.

[23] Volkoff S, Touranchet A, Derriennic F. The statistical study of the links between age, work and health and the ESTEV survey example. In: Marqui? JC, Paumès Cau-Bareille D, Volkoff S, editors. Working with age. London: Taylor and Francis, 1998.

[24] Ilmarinen J. Aging and work-coping with strengths and weaknesses. Scand J Work Environ Health. 1997; 23 Suppl 1: 3-5.

[25] Ilmarinen J. The ageing workforce - challenges for occupational health. Occup Med (Lond). 2006; 56(6): 362-4.

[26] Ilmarinen J. The Work Ability Index (WAI). Occup Med (Lond). 2007; 57(2): 160

[27] Ilmarinen J. Work ability - a comprehensive concept for occupational health research and prevention. Scand J Work Environ Health. 2009; 35(1): 1-5.

[28] Subramanian S, Huijts T, Avendano M. Self-reported health assessments in the 2002 World Health Survey: How do they correlate with education? Bull World Health Organ. 2010; 88(2): 131-8

[29] Derriennic F, Touranchet A, Volkoff S. Âge, travail, santé: études sur les salariés âgés de 37 à 52 ans, Estev 1990 Paris Inserm, 1996.

[30] Karasek R, Theorell T. Healthy Work: Stress, Productivity, and the Reconstruction of Working Life. New York: Basic Books, 1991

[31] Siegrist J. Adverse Health Effects of High-effort/Low-Reward Conditions. J Occup Health Psychol. 1996; 1(1): 27-41.

[32] Prévot E, Benzekri le Louet A, Bayon V, Choudat D, Leger D. Aspects réglementaires du travail post?et du travail de nuit. Arch Mal Prof Environ. 2009; 70(3): 262-71.

[33] Hulvej Rod N, Vahtera J, Westerlund H, Kivimaki M, Zins M, Goldberg M, Lange T. Sleep disturbances and cause-specific mortality: Results from the GAZEL cohort study. Am J Epidemiol. 2010; 173(3): 300-9.

[34] Straif K, Baan R, Grosse Y, et al. Carcinogenicity of shiftwork, painting, and fire-fighting. Lancet Oncol. 2007; 8: 1065-6.
[35] Stevens RG, Hansen J, Costa G, Haus E, Kauppinen T, Aronson KJ, Castaño-Vinyals G, Davis S, Frings-Dresen MHW, Fritschi L, Kogevinas M, Kogi K, Lie JA, Lowden A, Peplonska B, Pesch B, Pukkala E, Schernhammer E, Travis RC, Vermeulen R, Zheng T, Cogliano V, Straif K. Considerations of circadian impact for defining 'shift work' in cancer studies: IARC Working Group Report. Occup Environ Medicine 2011; 68(2): 154-62.

[36] Goldberg M, Leclerc A. Cohorte GAZEL, 20.000 volontaires d'EDF-GDF pour la recherché médicale. Bilan 1989-1993. Paris: Les éditions INSERM, 1994.

[37] Westerlund H, Kivimaki M, Singh-Manoux A, Melchior M, Ferrie JE, Pentti J, Jokela M, Leineweber C, Goldberg M, Zins M, Vahtera J. Self-rated health before and after retirement in France (GAZEL): a cohort study. Lancet. 2009; 374(9705): 1889-96.

[38] Vahtera J, Westerlund H, Hall M, Sjosten N, Kivimaki M, Sal OP, Ferrie JE, Jokela M, Pentti J, Singh-Manoux A, Goldberg M, Zins M. Effect of retirement on sleep disturbances: the GAZEL prospective cohort study. Sleep. 2009; 32(11): 145966.

[39] Singh-Manoux A, Gimeno D, Kivimaki M, Brunner E, Marmot MG. Low HDL cholesterol is a risk factor for deficit and decline in memory in midlife: the Whitehall II study. Arterioscler Thromb Vasc Biol. 2008; 28(8): 1556-62.

[40] Arendt H, editor. The human Condition. Chicago: University of Chicago Press, 1958.

[41] Fraser L, McKenna K, Turpin M, Allen S, Liddle J. Older workers: An exploration of the benefits, barriers and adaptations for older people in the workforce. WORK: A journal of Prevention, Assessment and Rehabilitation. 2009; 33(3): 26172.

[42] Bambrick P, Bonder B. Older adults' perceptions of work. WORK: A journal of Prevention, Assessment and Rehabilitation. $2005 ; 24(1)$ : 77-84.

[43] Dessors D, Schram J, Volkoff S. Du < handicap de situation> à la sélection-exclusion: une étude des conditions de travail antérieures aux licenciements économiques. Travail et Emploi. 1991; 48(02): 31-47. 